\title{
Identification of favorable subgroups for alternative anti-androgen therapy in castration-resistant prostate cancer
}

\author{
KOTARO SUZUKI, TOMOAKI TERAKAWA, KATSUMI SHIGEMURA, JUNYA FURUKAWA, \\ KENICHI HARADA, NOBUYUKI HINATA, YUZO NAKANO and MASATO FUJISAWA \\ Division of Urology, Kobe University Graduate School of Medicine, Kobe, Hyogo 650-0017, Japan
}

Received December 14, 2018; Accepted June 27, 2019

DOI: $10.3892 / \mathrm{mco} .2019 .1915$

\begin{abstract}
Although alternative anti-androgen therapy (switching to secondary anti-androgens) is no longer recommended in the clinical guidelines of prostate cancer in light of the new hormonal and cytotoxic agents available, this therapy has proven beneficial for some patients with castration-resistant prostate cancer (CRPC). The objective of this study was to identify favorable subgroups for alternative anti-androgen therapy among CRPC patients. Eighty-eight consecutive CRPC patients treated with alternative anti-androgen therapy were included in this study. All patients were treated with bicalutamide in the initial maximum androgen blockade (MAB) and switched to flutamide in the subsequent alternative anti-androgen therapy, combined with a luteinizing hormone-releasing hormone analogue. Several clinical and pathological factors for predicting the prostate-specific antigen (PSA) decline and PSA progression-free survival (PSA-PFS) of alternative anti-androgen therapy were investigated. Of all patients, 45 (51.1\%) patients showed $\geq 50 \%$ PSA decline. The median PSA-PFS was 7.5 months [95\% confidence interval (CI), 5.7-10.3]. Notably, 15 $(17.0 \%)$ patients had a PSA-PFS over 2 years. A multivariate analysis showed that $\geq 3$ bone metastatic lesions and a duration $<12$ months of initial MAB were significant factors shortening the duration of PSA-PFS, with hazard ratios of 2.11 (95\% CI, 1.23-3.62; $\mathrm{P}=0.007)$ and 2.08 (95\% CI, 1.20-3.57; $\mathrm{P}=0.008$ ), respectively. Patients without any of these factors had a median PSA-PFS of 22.8 months (95\% CI, 6.7-48.8). The overall survival in patients with $a \geq 7.5$-month PSA-PFS receiving alternative anti-androgen therapy was significantly longer than that of patients with a $<7.5$-month PSA-PFS (109.1 vs. 40.8 months; $\mathrm{P}<0.001)$. In conclusion, a longer duration of initial MAB and
\end{abstract}

Correspondence to: Dr Kotaro Suzuki, Division of Urology, Kobe University Graduate School of Medicine, 7-5-1 Kusunoki-cho, Chuo-ku, Kobe, Hyogo 650-0017, Japan

E-mail: pikataro1012@gmail.com

Key words: alternative anti-androgen therapy, secondary hormonal therapy, castration-resistant prostate cancer, prostate-specific antigen response, prostate-specific antigen progression-free survival, flutamide the absence of severe bone metastasis may predict a favorable response to alternative anti-androgen therapies in CRPC patients. Alternative anti-androgen therapy may still be beneficial for these patients, but this needs to be investigated further.

\section{Introduction}

Androgen deprivation therapy (ADT) is the standard treatment for patients with newly diagnosed metastatic prostate cancer and for those with recurrent prostate cancer after failure of localized therapy (1). Most of these patients have initially a good response to ADT, in which a luteinizing hormone-releasing hormone (LH-RH) analogue is combined with a nonsteroidal anti-androgen, such as bicalutamide or flutamide. However, the disease usually progresses to a castration-resistant state within 12-30 months (2).

No study so far, has demonstrated a definitive survival benefit (3), but secondary hormonal therapy, such as anti-androgen withdrawal, alternative anti-androgens, estrogenic compounds, and adrenolytic agents, has been used for patients with castration-resistant prostate cancer (CRPC) prior to docetaxel (4). However, the recent management of CRPC is sequential therapy using new hormonal or cytotoxic agents that have a demonstrable survival advantages in randomized clinical studies (5-11). Therefore, with these new agents available, secondary hormonal therapy is no longer recommended (12).

Nevertheless, in clinical practice, secondary hormonal therapy has proven beneficial for some patients with CRPC. In particular, alternative anti-androgen therapy (switching to secondary anti-androgens) (1), is still widely performed in Asian countries, and some CRPC patients show a good response to it (13-18). Furthermore, a previous retrospective study reported that a history of switching to a second-line anti-androgen therapy did not influence the overall survival (OS) with the new hormonal agent abiraterone acetate (4). This may suggest that the OS of patients with CRPC may be prolonged based on the response duration of alternative anti-androgen therapy; which may mean that patients with a long response to this therapy may have a particular benefit. These findings suggest that alternative anti-androgens may be beneficial for selected patients with CRPC prior to the administration of new hormonal agents. In addition, elderly patients and those with comorbidities are often treated with alternative anti-androgens instead of new hormonal agents 
in the actual clinical setting, and patients also often select alternative anti-androgens, considering the treatment cost as well as the efficacy, in developing countries (4).

The objective of this retrospective study was to re-evaluate alternative anti-androgen therapies for CRPC and to identify subgroups in whom this therapy may be beneficial.

\section{Patients and methods}

Patients. Eighty-eight patients with histologically confirmed advanced prostate cancer who were treated with alternative anti-androgen therapy following the failure of initial maximum androgen blockade (MAB) at Kobe University Hospital in Japan between January 2012 and September 2017 were included in this retrospective study. The study design was approved by the Research Ethics Committee of our institution (no. 180301), and was conducted in accordance with the Declaration of Helsinki. All patients gave their informed consent, and patient anonymity was preserved.

Evaluation of prostate cancer. The pathological findings were determined by systematic ultrasonography-guided needle biopsy, and the Gleason score was calculated according to the 2005 ISUP classification (19). The disease was clinically staged according to the 2010 TNM classification using magnetic resonance imaging, computed tomography, and bone scintigraphy. Diseases progression was defined as a $\geq 25 \%$ increase and an absolute increase of $\geq 2 \mathrm{ng} / \mathrm{ml}$ from the nadir in the serum prostate-specific antigen (PSA) value despite effective suppression of serum testosterone, according to the Prostate Cancer Working Group 2 criteria (20). The PSA decline was evaluated at $\geq 4$ weeks after the initiation of treatment. The serum PSA level was examined at least once every 12 weeks using a chemiluminescent enzyme immunoassay.

Treatment. All patients were treated with medical castration using a LH-RH analogue, Leuprorelin Acetate (3.75 mg/4 weeks; Takeda Pharmaceutical Company, Ltd.) or Goserelin acetate ( $3.6 \mathrm{mg} / 4$ weeks; AstraZeneca), plus bicalutamide $(80 \mathrm{mg} / \mathrm{day})$ in the initial MAB (18). If failure of the initial MAB was confirmed based on the definition or criteria shown above, patients were diagnosed with CRPC, and bicalutamide was discontinued. Of the 88 patients, 68 (77.3\%) patients were evaluated for the presence of anti-androgen withdrawal syndrome (AWS), and alternative anti-androgen therapy, using a LH-RH analogue plus flutamide ( $375 \mathrm{mg} /$ day), was then started (18). The remaining $20(22.7 \%)$ patients were administered alternative anti-androgen therapy, as mentioned above without being evaluated for AWS.

In the clinical strategy used since January 2016, alternative anti-androgens were used only by the patients, who may not immediately have to be treated with docetaxel: Those with a $\geq 12$-month response to initial MAB, who are asymptomatic or have minimally symptomatic disease or have no visceral disease (21). However, there were no clear indications for this treatment prior to January 2016.

Statistical analysis. The PSA decline, PSA progression-free survival (PSA-PFS) and OS of alternative anti-androgen therapy were investigated in the present study. To determine the factors for predicting the PSA decline, Student's t-test and Fisher's exact test were performed in Table II. For multiple comparisons in Table III, Fisher's exact test followed by Bonferroni post hoc test was used. The PSA-PFS and OS were estimated using the Kaplan-Meier method, and several potential factors, including age, initial PSA level, TNM classification, history of radical treatment and response to initial MAB, for predicting a longer PSA-PFS with alternative anti-androgen therapy were assessed using the Cox proportional hazards model.

For all statistical analyses, EZR was used (http://www. jichi.ac.jp/saitama-sct/SaitamaHP.files/statmedEN.html; Saitama Medical Center, Jichi Medical University), which is a graphical user interface for R (22). It is a modified version of $\mathrm{R}$ commander designed to add statistical functions frequently used in biostatistics. Each test was 2 -sided and $\mathrm{P}<0.05$ was considered to indicate a statistically significant difference.

\section{Results}

Patients characteristics. The characteristics of the 88 patients are shown in Table I. The median PSA value at the induction of initial MAB was $96.1 \mathrm{ng} / \mathrm{ml}$ (range, 0.218-22,412). Thirty-two (36.3\%) patients showed clinical T4 stage, and a $\geq 8$ Gleason score was found in $70(79.6 \%)$ patients. Prior prostatectomy and primary radiation therapy were performed in $9(10.2 \%)$ and $4(4.5 \%)$ patients, respectively. The median duration of the initial MAB was 15.7 months (range, 2.3-128.7), and the initial MAB was effective for over 12 months in 60 (68.2\%) patients. In addition, no one showed any adverse events related to flutamide.

PSA decline and PSA-PFS of alternative antiandrogen therapy. Firstly, the PSA decline of an alternative anti-androgen therapy was evaluated. The waterfall plots of the PSA decline showed that $61(69.3 \%)$ patients had some amount of decline, and 45 $(51.1 \%)$ had $\geq 50 \%$ PSA decline (Fig. 1A). The associations between several potential risk factors and the PSA decline was investigated next, but no significant factor for predicting any amount of PSA decline or $\geq 50 \%$ PSA decline was identified (Table II).

Next, the PSA-PFS of the alternative anti-androgen therapy was analyzed. As shown in Fig. 1B, the median PSA-PFS was 7.5 months [95\% confidence interval (CI), 5.7-10.3]. Notably, alternative anti-androgen therapy was effective for over 2 years in $15(17.0 \%)$ patients. A multivariate analysis showed that $\geq 3$ bone metastatic lesions and a duration $<12$ months of initial MAB were significant factors for predicting a shorter PSA-PFS, with hazard ratios of 2.11 (95\% CI, 1.23-3.62; $\mathrm{P}=0.007$ ) and 2.08 (95\% CI, 1.20-3.57; $\mathrm{P}=0.008$; Table III), respectively. PSA-PFS curves based on these two factors are shown in Fig. 2A and B. The median PFS of patients with $\leq 2$ and $\geq 3$ bone metastatic lesions was 17.9 months and 5.1 months (Fig. 2A), and that with a duration $<12$ months and $\geq 12$ months of initial MAB was 4.3 months and 11.3 months, respectively (Fig. 2B). The association between the PSA-PFS and the number of each of these two risk factors $(\geq 3$ bone metastatic lesions and a duration $<12$ months of initial MAB) was further investigated. The number of the above risk factors had no impact on the PSA decline (Fig. 3A), but the PSA-PFS of patients without these factors was markedly longer than that 
Table I. Patient characteristics.

Period of observation, median (range), months

Age, median (range), years

T stage, $\mathrm{n}(\%)$

$\leq \mathrm{T} 2$

$13(14.8)$

T3

43 (48.9)

T4

$32(36.3)$

Gleason score, n (\%)

$\leq 7$

18 (20.4)

8

38 (43.2)

$27(30.7)$

10

Site of disease, n (\%)

None

Bone

1 or 2 lesions

$18(20.5)$

$\geq 3$ lesions

43 (14.3)

Lymph node

$43(14.3)$

Visceral

$7(8.0)$

Prior prostatectomy or primary radiation, n (\%)

Prostatectomy

Primary radiation

PSA at baseline, median (range), $\mathrm{ng} / \mathrm{ml}$

Duration of initial MAB, median (range), months

Anti-androgen withdrawal, n (\%)

Yes

19 (21.6)

No

$49(55.7)$

Not assessed

$20(22.7)$

$\mathrm{N}=88$. PSA, prostate-specific antigen; MAB, maximum androgen blockade.

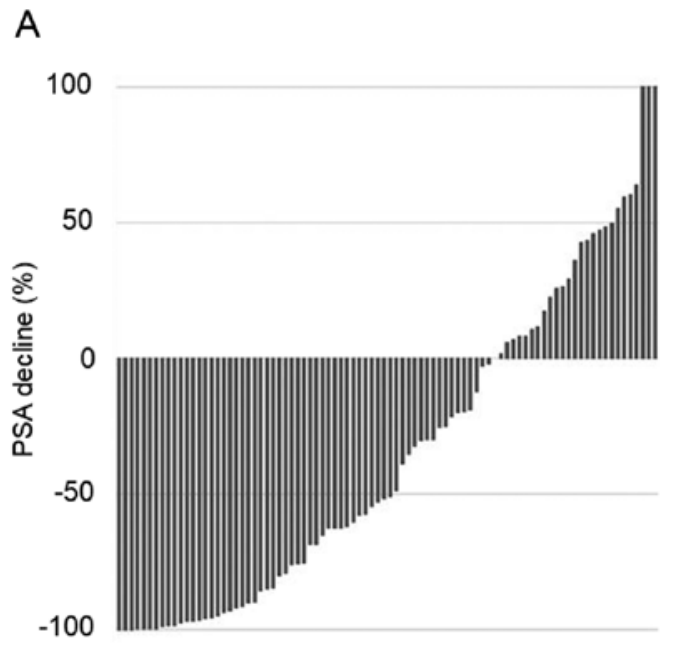

B

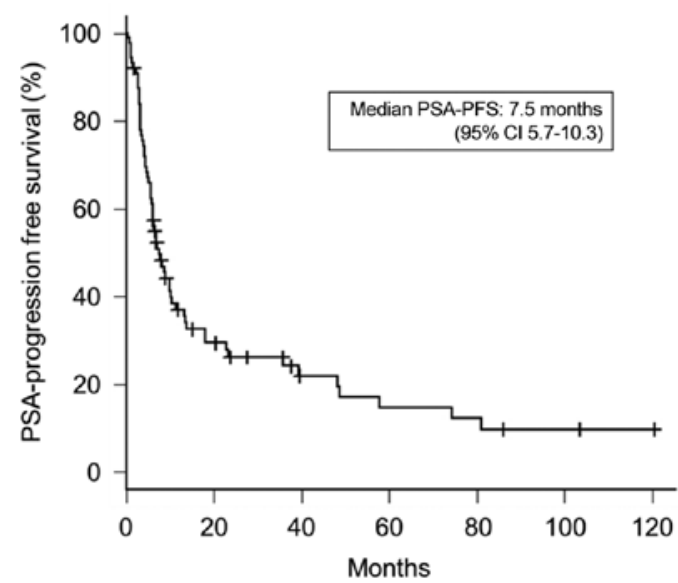

Figure 1. Clinical efficacy of the enrolled patients treated with alternative anti-androgen therapy. (A) Waterfall plot representing the percentage of the best response in PSA. (B) The Kaplan-Meier curve for the PSA progression-free survival. PSA, prostate-specific antigen; PFS, progression-free survival.

of patients with 1 or 2 factors (Fig. 3B, the median PSA-PFS was 22.8 months vs. 6.7 months or 3.5 months, respectively;
$\mathrm{P}<0.001$ ), which suggests that these factors had an additive impact on PSA-PFS. 
Table II. Association between several parameters and for PSA decline of alternative anti-androgen therapy.

\begin{tabular}{|c|c|c|c|c|c|c|}
\hline \multirow[b]{2}{*}{$\mathrm{N}=88$} & \multicolumn{3}{|c|}{ Any PSA decline } & \multicolumn{3}{|c|}{$\geq 50 \%$ PSA decline } \\
\hline & Yes $(n=61)$ & No $(n=27)$ & P-value & Yes $(n=45)$ & No $(n=43)$ & P-value \\
\hline Mean age (range), years & $74.5(52-88)$ & $74.1(56-90)$ & 0.844 & $73.5(52-88)$ & $75.3(56-90)$ & 0.311 \\
\hline $\begin{array}{l}\text { Mean PSA at the induction of } \\
\text { initial MAB (range), } \mathrm{ng} / \mathrm{ml}\end{array}$ & $\begin{array}{c}950.3 \\
(0.218-22,412)\end{array}$ & $\begin{array}{c}1,430.9 \\
(0.718-21,439)\end{array}$ & 0.548 & $\begin{array}{c}1,252.0 \\
(0.218-22,412)\end{array}$ & $\begin{array}{c}936.3 \\
(0.438-21,439)\end{array}$ & 0.669 \\
\hline $\begin{array}{l}\text { T stage, } \mathrm{n}(\%) \\
\leq \mathrm{T} 3 \\
\geq \mathrm{T} 4\end{array}$ & $\begin{array}{l}47(77.0) \\
14(23.0)\end{array}$ & $\begin{array}{c}22(81.5) \\
5(18.5)\end{array}$ & 0.782 & $\begin{array}{l}34(75.6) \\
11(24.4)\end{array}$ & $\begin{array}{l}35(81.4) \\
8(18.6)\end{array}$ & 0.607 \\
\hline $\begin{array}{l}\text { Gleason score, } \mathrm{n}(\%) \\
\leq 7 \\
\geq 8\end{array}$ & $\begin{array}{l}14(23.0) \\
47(77.0)\end{array}$ & $\begin{array}{c}4(14.8) \\
23(85.2)\end{array}$ & 0.568 & $\begin{array}{l}10(22.2) \\
35(77.8)\end{array}$ & $\begin{array}{c}8(18.6) \\
35(81.4)\end{array}$ & 0.793 \\
\hline $\begin{array}{l}\text { Lymph node metastasis, n (\%) } \\
\text { No } \\
\text { Yes }\end{array}$ & $\begin{array}{l}30(49.2) \\
31(50.8)\end{array}$ & $\begin{array}{l}15(55.6) \\
12(44.4)\end{array}$ & 0.648 & $\begin{array}{l}22(48.9) \\
23(51.1)\end{array}$ & $\begin{array}{l}23(53.5) \\
20(46.5)\end{array}$ & 0.677 \\
\hline $\begin{array}{l}\text { Bone metastasis, n (\%) } \\
\text { No } \\
\text { Yes }\end{array}$ & $\begin{array}{l}20(32.8) \\
41(67.2)\end{array}$ & $\begin{array}{c}8(29.6) \\
19(70.4)\end{array}$ & 0.648 & $\begin{array}{l}13(28.9) \\
32(71.1)\end{array}$ & $\begin{array}{l}15(34.9) \\
28(65.1)\end{array}$ & 0.649 \\
\hline $\begin{array}{l}\text { Lesions of bone metastasis, } \mathrm{n}(\%) \\
\leq 2 \\
\geq 3\end{array}$ & $\begin{array}{l}35(57.4) \\
26(42.6)\end{array}$ & $\begin{array}{l}10(37.0) \\
17(63.0)\end{array}$ & 0.106 & $\begin{array}{l}24(53.3) \\
21(46.7)\end{array}$ & $\begin{array}{l}21(48.8) \\
22(51.2)\end{array}$ & 0.831 \\
\hline $\begin{array}{l}\text { Visceral metastasis, n (\%) } \\
\text { No } \\
\text { Yes }\end{array}$ & $\begin{array}{l}55(90.2) \\
6(9.8)\end{array}$ & $\begin{array}{c}26(96.3) \\
1(3.7)\end{array}$ & 0.431 & $\begin{array}{c}41(91.1) \\
4(8.9)\end{array}$ & $\begin{array}{c}40(93.0) \\
3(7.0)\end{array}$ & 1.000 \\
\hline $\begin{array}{l}\text { Prior prostatectomy or primary } \\
\text { radiation, } \mathrm{n}(\%)\end{array}$ & & & 0.747 & & & 0.770 \\
\hline $\begin{array}{l}\text { No } \\
\text { Yes }\end{array}$ & $\begin{array}{l}51(83.6) \\
10(16.4)\end{array}$ & $\begin{array}{c}24(88.9) \\
3(11.1)\end{array}$ & & $\begin{array}{c}39(86.7) \\
6(13.3)\end{array}$ & $\begin{array}{c}36(83.7) \\
7(16.3)\end{array}$ & \\
\hline $\begin{array}{l}\text { Mean duration of initial MAB } \\
\text { (range), months }\end{array}$ & $27.9(3.3-128.7)$ & $22.4(2.3-99.7)$ & 0.360 & $25.5(3.3-128.7)$ & $26.9(2.3-106.9)$ & 0.799 \\
\hline $\begin{array}{l}\text { Anti-androgen withdrawal, n (\%) } \\
\text { No or not assessed } \\
\text { Yes }\end{array}$ & $\begin{array}{l}47(77.0) \\
14(23.0)\end{array}$ & $\begin{array}{c}22(81.5) \\
5(18.5)\end{array}$ & 0.782 & $\begin{array}{l}34(75.6) \\
11(24.4)\end{array}$ & $\begin{array}{l}35(81.4) \\
8(18.6)\end{array}$ & 0.607 \\
\hline
\end{tabular}

PSA, prostate-specific antigen; MAB, maximum androgen blockade.

OS of alternative antiandrogen therapy. As shown in Fig. 4, the median OS was 109.1 months (95\% CI, 58.1-NA), and the OS of patients with $\geq 7.5$ months of PSA-PFS of alternative anti-androgen therapy was significantly longer than that of patients with $<7.5$ months of therapy (Fig. 4B; median OS, 109.1 months vs. 40.8 months, respectively; $\mathrm{P}<0.001)$.

\section{Discussion}

Alternative anti-androgens are widely used as secondary hormonal therapy to treat CRPC, but none have demonstrated a survival advantage in previous studies (3). In Asian countries, including Japan, several retrospective studies have shown that alternative anti-androgens were effective for some patients (13-18), and hormonal therapy may be a viable treatment, especially for Japanese patients, not only with respect to effectiveness on cancer control but adverse events as well $(23,24)$. Furthermore, alternative anti-androgen has shown significant efficacy in certain clinical settings. Therefore, alternative anti-androgens may be beneficial for selected patients with CRPC, especially those in Asian countries, including Japan, prior to treatment with docetaxel.

Several reports have evaluated the effectiveness of alternative anti-androgens. Yokomizo et al (14) found a PSA decrease $\geq 50 \%$ in $40 \%$ of patients who immediately switched from bicalutamide to flutamide as a second-line MAB, and Okihara et al (25) reported that $38 \%$ of patients achieved a $\geq 50 \%$ PSA decline on changing from bicalutamide to flutamide, with a median PSA-PFS of 5.1 months. Yasui et al (15) showed that the median duration of PSA-PFS was 4.6 months in patients with metastatic CRPC treated with alternative anti-androgens. In the present study, it was found that 45 of $88(51.1 \%)$ patients had a $\geq 50 \%$ PSA decline, and the median duration of PSA-PFS was 7.5 months, which was relatively better than that in the aforementioned 
Table III. Univariate and multivariate analyses of several parameters for predicting PSA-PFS.

\begin{tabular}{|c|c|c|c|c|}
\hline \multirow[b]{2}{*}{$\mathrm{N}=88$} & \multicolumn{2}{|c|}{ Univariate analysis } & \multicolumn{2}{|c|}{ Multivariate analysis } \\
\hline & $\mathrm{HR}(95 \% \mathrm{CI})$ & P-value & $\mathrm{HR}(95 \% \mathrm{CI})$ & P-value \\
\hline Age $(<75$ vs. $\geq 75)$, years & $1.19(0.72-1.92)$ & 0.493 & - & - \\
\hline PSA at the induction of initial MAB, $(\geq 100$ vs. $<100), \mathrm{ng} / \mathrm{ml}$ & $1.08(0.66-1.76)$ & 0.765 & - & - \\
\hline T stage ( $\geq \mathrm{T} 4$ vs. $\leq \mathrm{T} 3)$ & $1.23(0.69-2.21)$ & 0.480 & - & - \\
\hline Gleason score ( $\geq 8$ vs. $\leq 7$ ) & $1.95(1.01-3.75)$ & 0.047 & $1.81(0.89-3.67)$ & 0.104 \\
\hline Lymph node metastasis (yes vs. no) & $1.25(0.76-2.04)$ & 0.375 & - & - \\
\hline Bone metastasis (yes vs. no) & $1.97(1.11-3.48)$ & 0.020 & $1.03(0.46-2.33)$ & 0.945 \\
\hline Lesions of bone metastasis ( $\geq 3$ vs. $\leq 2$ ) & $2.53(1.52-4.20)$ & $<0.001$ & $2.11(1.23-3.62)$ & 0.007 \\
\hline Visceral metastasis (yes or no) & $1.08(0.43-2.70)$ & 0.877 & - & - \\
\hline Prior prostatectomy or primary radiation (no or yes) & $2.08(1.00-4.35)$ & 0.051 & - & - \\
\hline Duration of initial MAB ( $<12$ vs. $\geq 12)$, months & $2.63(1.56-4.35)$ & $<0.001$ & $2.08(1.20-3.57)$ & 0.008 \\
\hline Anti-androgen withdrawal (no vs. yes) & $1.59(0.85-2.94)$ & 0.141 & - & - \\
\hline
\end{tabular}

PSA, prostate-specific antigen; MAB, maximum androgen blockade; HR, hazard ratio; CI, confidence interval.

A

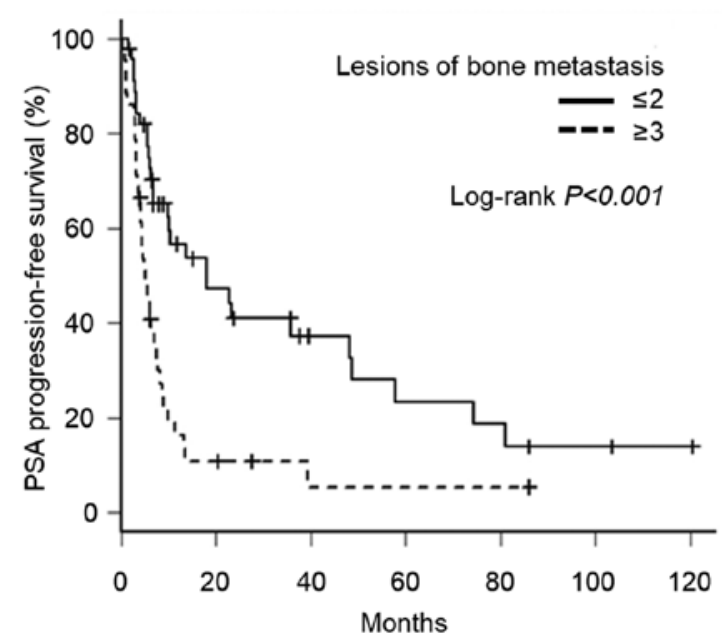

B

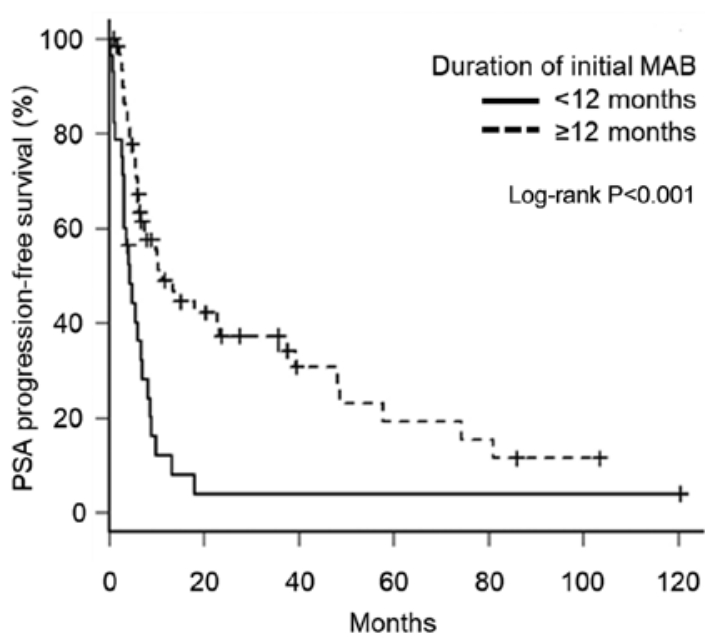

Figure 2. Kaplan-Meier estimates of the PSA progression-free survival based on (A) the number of lesions of bone metastasis and (B) the duration of initial MAB. PSA, prostate-specific antigen; MAB, maximum androgen blockade.

studies. This is probably due to the present treatment strategy, as it was decided to use this therapy only for patients who may not immediately have to be treated with docetaxel (such as those with a $\geq 12$-month response to initial MAB, who are asymptomatic or have minimally symptomatic disease or have no visceral disease), as mentioned in a previous report (21). Thus, this favorable result may reflect our selective use of alternative anti-androgens.

However, despite these findings, the PSA response to alternative anti-androgens of the present study was inferior to that of enzalutamide and abiraterone acetate shown in a randomized clinical study. In the PREVAIL study, $78 \%$ of patients treated with enzalutamide had a $\geq 50 \%$ PSA decline, and the median PSA-PFS was 11.2 months (10). In the COU-AA-302 trial, the PSA decreased $\geq 50 \%$ in $62 \%$ of patients treated with abiraterone acetate plus prednisone, and the median PSA-PFS was 11.1 months (26). However, while previous reviews have indicated that switching to docetaxel immediately after the failure of initial ADT is preferred for patients who are suspected of having androgen receptor axis-targeted treatment resistance $(21,27)$, whether or not new hormonal agents, such as enzalutamide or abiraterone acetate, should be considered immediately over alternative anti-androgen therapy following prior ADT remains unclear. Randomized controlled trials comparing the efficacy of flutamide and enzalutamide (Trial registration: ClinicalTrials.gov no. NCT02918968) or abiraterone acetate (Trial registration: UMIN-CTR no. UMIN000016617) are currently being carried out, and the results of these trials may resolve this issue.

For predictive factors of second-line anti-androgens, CRPC patients with a better clinical response, such as a better PSA response, longer duration of response and shorter time to PSA nadir, in the first MAB or without severe metastasis offered a better PSA response to alternative anti-androgen therapy $(13-15,18)$. In the present study, it was shown that 
A

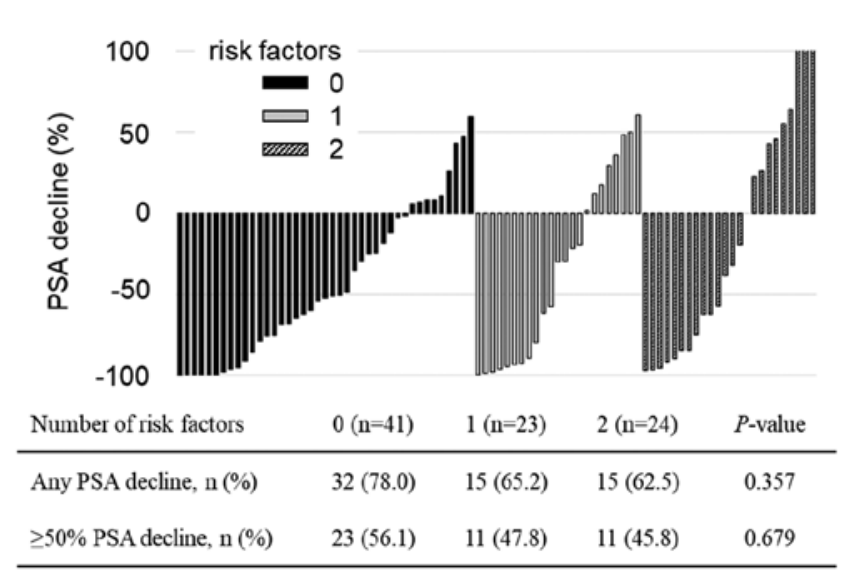

B

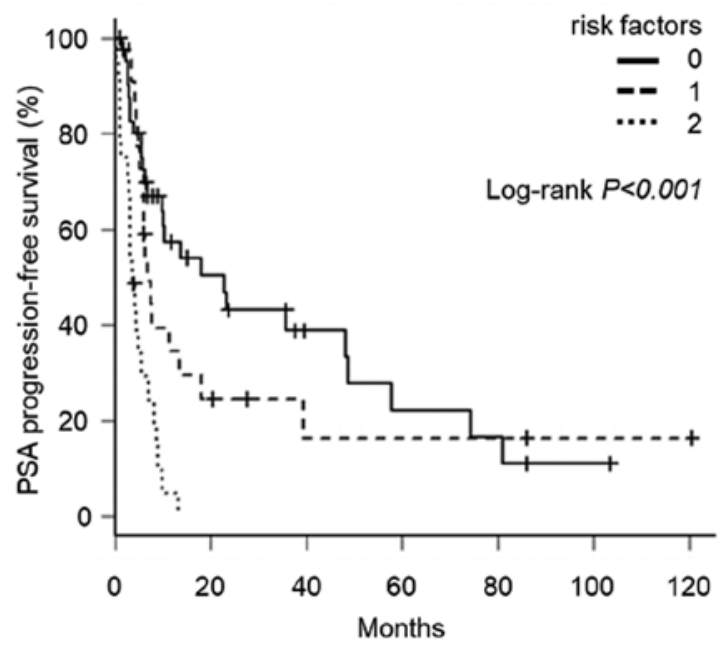

Figure 3. Association of clinical efficacy and number of risk factors. (A) Waterfall plot representing the percentage of the best response in PSA (upper) and comparisons of PSA decline (lower) in subgroups based on the number of risk factors. (B) Kaplan-Meier curve for the PSA progression-free survival based on the number of risk factors. PSA, prostate-specific antigen.

A

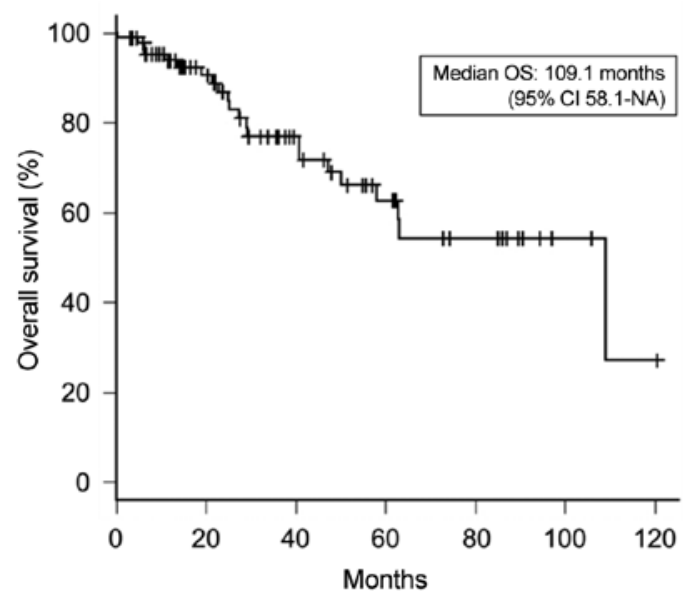

B

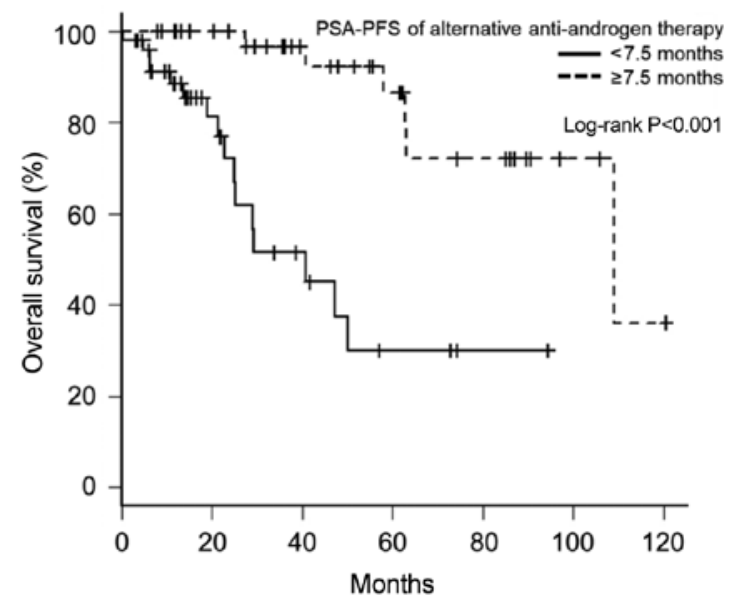

Figure 4. Kaplan-Meier curve for the overall survival of alternative anti-androgen therapy (A) in all patients and (B) based on the duration of the PSA progression-free survival with alternative anti-androgen therapy. PSA, prostate-specific antigen; PFS, progression-free survival; OS, overall survival.

patients with $\leq 2$ bone metastatic lesions and a duration $\geq 12$ months of initial MAB had a median PSA-PFS of 22.8 months. These findings suggest that the effectiveness of the initial MAB and the severity of metastasis may strongly influence the therapeutic efficacy of the subsequent alternative anti-androgen therapy, and these results may be useful for determining the selective introduction of alternative anti-androgens. In addition, it was also shown that patients with a longer PSA-PFS with alternative anti-androgens had a prolonged OS, suggesting that alternative anti-androgen therapy may be beneficial for these selected patients.

One concern is whether or not alternative anti-androgen therapy will affect the therapeutic response of newly developed hormonal agents. Zhao et al (4) reported that switching to flutamide did not influence the OS of abiraterone acetate in patients with metastatic CRPC, which suggests that the OS of patients with CRPC may be prolonged based on the response duration of alternative anti-androgen therapy. Nakai et al (28) showed that patients for whom second-line flutamide was effective had a better response to subsequent abiraterone acetate than those for who the treatment proved to be ineffective. In a preclinical setting, Prekovic et al (29) showed that the combination of the androgen receptor (AR) F877L mutation, which leads to enzalutamide resistance, and the AR T878A mutation, which is often found in flutamide-treated patients, causes enzalutamide to have strong agonistic activity, but that only the F877L mutation has a weak effect on enzalutamide binding, which suggests that the prior administration of flutamide may enhance enzalutamide resistance. These findings indicate that the influence of alternative anti-androgen therapy on new hormonal agents is still controversial.

Even though no study has demonstrated a definitive survival benefit of alternative anti-androgen therapy, the present data suggest that there may be some subgroup for 
which alternative anti-androgens may be beneficial, even in this era of new agents. However, the present study had several limitations. Because the present study was a retrospective and single-arm study, caution should be given when interpreting the present results, considering the possibility that the new hormonal agents may be much more beneficial than alternative anti-androgens if they are used for CRPC patients with a longer duration of initial MAB response and the absence of severe metastasis. Therefore, further investigation, such as the randomized controlled trials that are currently being carried out, are necessary in order to decide whether or not to include alternative anti-androgen therapy in the treatment strategy of CRPC. In addition, not all patients were assessed for AWS, and some received localized therapy. Furthermore, disease progression was defined as an increased PSA level, but the metastasis-free survival and radiographic progression, which is the standard endpoint for new agents, were not assessed. Finally, because new hormonal and cytotoxic agents became available during the study period, the subsequent therapies applied after alternative anti-androgens varied. Therefore, the clinical outcome of subsequent therapies could not be evaluated in this retrospective analysis.

In conclusion, it was found that a longer duration of initial MAB and a lack of severe bone metastasis may predict a favorable response to alternative anti-androgens in CRPC patients. Furthermore, those with a favorable response to alternative anti-androgens had a longer OS than those with a poor response. Alternative anti-androgen therapy may still be beneficial for selected patients, especially in Asian countries, including Japan, and may be a viable choice for treating such patients, even in the era of novel agents.

\section{Acknowledgements}

Not applicable.

\section{Funding}

No funding was received.

\section{Availability of data and materials}

The datasets used and analyzed in the present study are available from corresponding author on reasonable request.

\section{Authors' contributions}

$\mathrm{KSu}, \mathrm{TT}, \mathrm{NH}, \mathrm{YN}$ and MF designed the study. KSu, TT, KSh, $\mathrm{JF}, \mathrm{KH}$ acquired and analyzed the data. KSu, TT and KSh drafted the manuscript, and $\mathrm{KH}, \mathrm{JF}, \mathrm{NH}, \mathrm{YN}$ and $\mathrm{MF}$ revised it critically for important intellectual content. All authors gave final approval of the version to be published.

\section{Ethics approval and consent to participate}

The study design was approved by the Research Ethics Committee of Kobe University Hospital (no. 180301), which was conducted in accordance with the Declaration of Helsinki. All patients gave informed consent, and patient anonymity was preserved.

\section{Patient consent for publication}

Not applicable.

\section{Competing interests}

The authors declare that they have no conflicts of interest.

\section{References}

1. Lorente D, Mateo J, Zafeiriou Z, Smith AD, Sandhu S, Ferraldeschi R and de Bono JS: Switching and withdrawing hormonal agents for castration-resistant prostate cancer. Nat Rev Urol 12: 37-47, 2015

2. Laufer M, Denmeade SR, Sinibaldi VJ, Carducci MA and Eisenberger MA: Complete androgen blockade for prostate cancer: What went wrong? J Urol 164: 3-9, 2000.

3. Heidenreich A, Bastian PJ, Bellmunt J, Bolla M, Joniau S, van der Kwast T, Mason M, Matveev V, Wiegel T, Zattoni F, et al: EAU guidelines on prostate cancer. Part II: Treatment of advanced, relapsing, and castration-resistant prostate cancer. Eur Urol 65: 467-479, 2014.

4. Zhao JG, Liu JD, Shen PF, Tang X, Sun GX, Zhang XM, Chen JR, Shu KP, Shi M and Zeng H: Prior switching to a second-line nonsteroidal antiandrogen does not impact the therapeutic efficacy of abiraterone acetate in patients with metastatic castration-resistant prostate cancer: A real-world retrospective study. Asian J Androl 20: 545-550, 2018.

5. de Bono JS, Oudard S, Ozguroglu M,Hansen S, Machiels JP, Kocak I, Gravis G, Bodrogi I, Mackenzie MJ, Shen L, et al: Prednisone plus cabazitaxel or mitoxantrone for metastatic castration-resistant prostate cancer progressing after docetaxel treatment: A randomised open-label trial. Lancet 376: 1147-1154, 2010.

6. Kantoff PW, Higano CS, Shore ND, Berger ER, Small EJ, Penson DF, Redfern CH, Ferrari AC, Dreicer R, Sims RB, et al: Sipuleucel-T immunotherapy for castration-resistant prostate cancer. N Engl J Med 363: 411-422, 2010.

7. Fizazi K, Scher HI, Molina A, Logothetis CJ, Chi KN, Jones RJ, Staffurth JN, North S, Vogelzang NJ, Saad F, et al: Abiraterone acetate for treatment of metastatic castration-resistant prostate cancer: Final overall survival analysis of the COU-AA-301 randomised, double-blind, placebo-controlled phase 3 study. Lancet Oncol 13: 983-992, 2012.

8. Scher HI, Fizazi K, Saad F, Taplin ME, Sternberg CN, Miller K, de Wit R, Mulders P, Chi KN, Shore ND, et al: Increased survival with enzalutamide in prostate cancer after chemotherapy. N Engl J Med 367: 1187-1197, 2012.

9. Parker C, Nilsson S, Heinrich D, Helle SI, O'Sullivan JM, Fosså SD, Chodacki A, Wiechno P, Logue J, Seke M, et al: Alpha emitter radium-223 and survival in metastatic prostate cancer. N Engl J Med 369: 213-223, 2013.

10. Beer TM, Armstrong AJ, Rathkopf DE, Loriot Y, Sternberg CN, Higano CS, Iversen P, Bhattacharya S, Carles J, Chowdhury $\mathrm{S}$, et al: Enzalutamide in metastatic prostate cancer before chemotherapy. N Engl J Med 371: 424-433, 2014.

11. Ryan CJ,Smith MR, Fizazi K, Saad F, Mulders PF, Sternberg CN, Miller K, Logothetis CJ, Shore ND, Small EJ, et al: Abiraterone acetate plus prednisone versus placebo plus prednisone in chemotherapy-naive men with metastatic castration-resistant prostate cancer (COU-AA-302): Final overall survival analysis of a randomised, double-blind, placebo-controlled phase 3 study. Lancet Oncol 16: 152-160, 2015.

12. Cornford P, Bellmunt J, Bolla M, Briers E, De Santis M, Gross T, Henry AM, Joniau S, Lam TB, Mason MD, et al: EAU-ESTRO-SIOG guidelines on prostate cancer. Part II: Treatment of relapsing, metastatic, and castration-resistant prostate cancer. Eur Urol 71: 630-642, 2017.

13. Momozono H, Miyake H, Tei H, Harada KI and Fujisawa M: Clinical outcomes of anti-androgen withdrawal and subsequent alternative anti-androgen therapy for advanced prostate cancer following failure of initial maximum androgen blockade. Mol Clin Oncol 4: 839-844, 2016.

14. Yokomizo Y, Kawahara T, Miyoshi Y, Otani M, Yamanaka S, Teranishi J, Noguchi K, Yao M and Uemura H: Efficacy of immediate switching from bicalutamide to flutamide as second-line combined androgen blockade. Biomed Res Int 2016: 4083183, 2016. 
15. Yasui M, Uemura K, Yoneyama S, Kawahara T, Hattori Y, Teranishi JI, Inoue M, Ohta JI, Yokomizo Y, Yao M, et al: Predictors of poor response to secondary alternative antiandrogen therapy with flutamide in metastatic castration-resistant prostate cancer. Jpn J Clin Oncol 2016 (Epub ahead of print).

16. Choi JI, Kim YB, Yang SO, Lee JK and Jung TY: Efficacy of alternative antiandrogen therapy for prostate cancer that relapsed after initial maximum androgen blockade. Korean J Urol 52: 461-465, 2011.

17. Okegawa T, Nutahara K and Higashihara E: Alternative antiandrogen therapy in patients with castration-resistant prostate cancer: A single-center experience. Int J Urol 17: 950-955, 2010.

18. Suzuki H, Okihara K, Miyake H, Fujisawa M, Miyoshi S, Matsumoto T, Fujii M, Takihana Y, Usui T, Matsuda T, et al: Alternative nonsteroidal antiandrogen therapy for advanced prostate cancer that relapsed after initial maximum androgen blockade. J Urol 180: 921-927, 2008.

19. Epstein JI, Allsbrook WC Jr, Amin MB and Egevad LL; ISUP Grading Committee: The 2005 international society of urological pathology (ISUP) consensus conference on gleason grading of prostatic carcinoma. Am J Surg Pathol 29: 1228-1242, 2005.

20. Scher HI, Halabi S, Tannock I, Morris M, Sternberg CN, Carducci MA, Eisenberger MA, Higano C, Bubley GJ, Dreicer R, et al: Design and end points of clinical trials for patients with progressive prostate cancer and castrate levels of testosterone: Recommendations of the prostate cancer clinical trials working group. J Clin Oncol 26: 1148-1159, 2008.

21. Chi K, Hotte SJ, Joshua AM, North S, Wyatt AW, Collins LL and Saad F: Treatment of mCRPC in the AR-axis-targeted therapy-resistant state. Ann Oncol 26: 2044-2056, 2015.

22. Kanda Y: Investigation of the freely available easy-to-use software 'EZR' for medical statistics. Bone Marrow Tranfsplant 48: 452-458, 2013
23. Fukagai T, Namiki TS, Carlile RG, Yoshida H and Namiki M: Comparison of the clinical outcome after hormonal therapy for prostate cancer between Japanese and Caucasian men. BJU Int 97: 1190-1193, 2006.

24. Namiki M, Ueno S, Kitagawa Y, Fukagai T and Akaza H: Effectiveness and adverse effects of hormonal therapy for prostate cancer: Japanese experience and perspective. Asian J Androl 14: 451-457, 2012.

25. Okihara K, Ukimura O, Kanemitsu N, Mizutani Y, Kawauchi A and Miki T; Kyoto Prefectural University of Medicine Prostate Cancer Research Group: Clinical efficacy of alternative antiandrogen therapy in Japanese men with relapsed prostate cancer after first-line hormonal therapy. Int J Urol 14: 128-132, 2007.

26. Ryan CJ, Smith MR, de Bono JS, Molina A, Logothetis CJ, de Souza P, Fizazi K, Mainwaring P, Piulats JM, Ng S, et al: Abiraterone in metastatic prostate cancer without previous chemotherapy. N Engl J Med 368: 138-148, 2013.

27. Fitzpatrick JM, Bellmunt J, Fizazi K, Heidenreich A, Sternberg CN, Tombal B, Alcaraz A, Bahl A, Bracarda S, Di Lorenzo G, et al: Optimal management of metastatic castration-resistant prostate cancer: Highlights from a European expert consensus panel. Eur J Cancer 50: 1617-1627, 2014.

28. Nakai Y, Tanaka N, Miyake M, Inoue T, Anai S and Fujimoto K: Response to flutamide, as second-line therapy after bicalutamide, predicts efficacy of abiraterone, not that of enzalutamide. BMC Res Notes 11: 342, 2018.

29. Prekovic S, van Royen ME, Voet AR, Geverts B, Houtman R, Melchers D, Zhang KY, Van den Broeck T, Smeets E, Spans L, et al: The effect of F877L and T878A mutations on androgen receptor response to enzalutamide. Mol Cancer Ther 15: 1702-1712, 2016. 